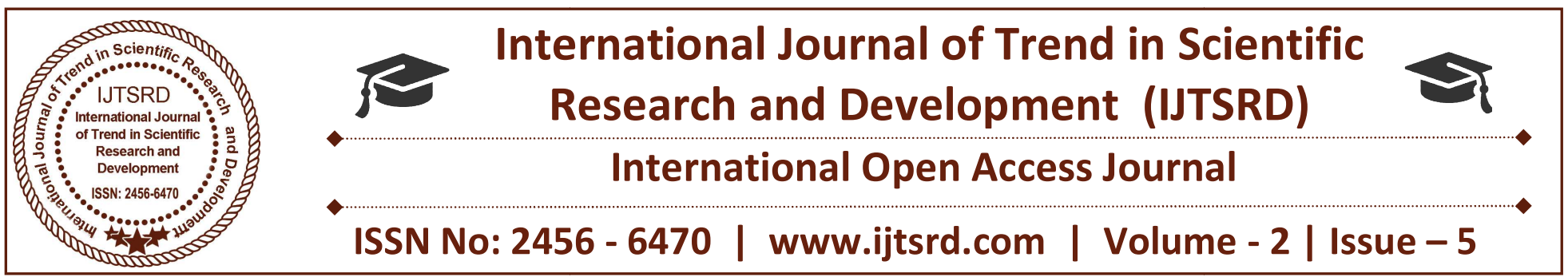

\title{
Removal of Fluoride by Adsorption Using Fuller's Earth
}

\author{
Ahmed Omer ${ }^{1}$, Prof. Dr. Shivasharnappa G Patil ${ }^{2}$ \\ ${ }^{1}$ M. Tech Research Scholar Environmental, ${ }^{2}$ Professor \\ Division of Civil Engineering Department, PDA College of Engineering, \\ Shambhognlli, Kalaburagi, Karnataka, India
}

\begin{abstract}
The presents study deals with the adsorption of fluoride by Fuller's Earth. Batch adsorption studies were carried for removal of fluoride by using Fuller's earth at different time, dosage and $\mathrm{pH}$. It is observed that percentage removal of fluoride is increases with the increases in contact time and dosage. The optimum contact time is $71 \%$ and Dosage is $73 \%$. The maximum removal of fluoride is obtained at a optimum $\mathrm{pH}$ of 7.0 with removal efficiency is 75.5\%.Freundlich and Langmuir adsorption isotherms are followed.
\end{abstract}

Keywords: Adsorption, flouride,Fuller's

earth.

\section{INTRODUCTION}

Water is life for all living beings. But nowadays, 'pure drinking water is Available to very few people. Others take more or less contaminated water. The Contamination may be caused either by natural forces or by industrial effluents. One Such contaminant is fluoride. Fluorine is the most highly reactive element of the halogen family. It exists in water mainly as fluoride ion. Fluoride has been described, as more toxic than lead and less toxic than arsenic and is considered as an Accumulative toxin.

The occurrence of high fluoride concentrations in ground water is a problem Faced by many countries, notably India, Sri Lanka, and China, the Rift Valley countries in East Africa, Turkey, and parts of South Africa. Fluoride related health hazards are a major Environmental problem in many regions of the world. India is among the 25 nations around the globe, where health problem occurs due to the consumption of fluoride contaminated Water.
It is estimated that around 260 million people worldwide (in 30 countries) are drinking water with Fluoride content more than $1.0 \mathrm{mg} / \mathrm{l}$. In India alone, endemic Fluoro sis is thought to affect around one million people and is a major problem in 17 of the 25 states, especially Rajasthan, Andhra Pradesh, Tamil Nadu, Gujarat and Uttar Pradesh.

\subsection{Effects of Fluoride Ingestion on Human Beings}

Fluoride has dual significance. If the fluoride content is less, then it may cause problems like dental carries. W.H.O has stated that it should be in the range of 0.1 to $0.5 \mathrm{ppm}$. By U.S. standard, the fluoride content in water should be between 0.6 and $0.9 \mathrm{ppm}$. The Indian Standard for fluoride contents is $1 \mathrm{ppm}$, this shows that the requirement of fluoride content changes and it depends on the geographical condition 1 the age of human beings. Intake of more than $6 \mathrm{mg}$ of fluoride per day results in Fluoride being a cumulative bone seeking mineral, the resultant skeletal changes are progressive. Fluoride ingested with water, goes on accumulating in bones up to the age of 55 years. At higher doses fluoride interfere with carbohydrates, lipid Proteins vitamin, enzyme and mineral metabolism. Therefore, pre-concentration or removal of fluoride from aqueous solutions is a matter of great concern in analytical and environmental works. Determination of fluoride in drinking water has received a considerable attention, due to its detrimental effects on health.

If affects young and old alike. An individual may suffer from

1. Skeletal fluorosis, or

2. Dental Fluorides, or 
3. Non-skeletal fluorosis,

4. All or a combination of the above.

\subsubsection{Skeletal Fluorosis}

Prevalence of skeletal fluorosis increases with increase in fluoride concentration and age. Following are the symptoms of skeletal fluorosis:

1. Severe pain and stiffness in the back bone

2. Severe pain and stiffness in joints

3. Severe pain and rigidity in hip region

4. X-ray: Increased girth/thickening and density of bone besides calcification of ligaments.

5. Paralysis

\subsubsection{Dental Fluorosis}

Dental fluorosis prominent in children who are brought up in an endemic area of fluorosis, Dental fluorosis can occur in milk teeth and the permanent teeth both. Discoloration due to excess fluoride intake will be visible to naked eye. Dental fluorosis occurs in human beings consuming water containing $1.5 \mathrm{mg} / \mathrm{I}$ or more of fluorides, particularly during the first eight years of life.

\subsubsection{Non-Skeletal Manifestations}

This aspect of fluorosis is often overlooked because of the wrong notion prevailing that fluoride will only affect bone and teeth. Fluoride when consumed in excess can cause several ailments besides skeletal and dental fluorosis.

\subsection{Material and Methods \\ Selection of Adsorbent:}

Fuller's Earth is any clay material that has the capability to decolorize oil or other liquids without chemical treatment. Modern uses of fuller's earth include absorbents for oil, grease, and animal waste (cat litter) and as a carrier for pesticides and fertilizers. Minor uses include filtering, clarifying, and decolorizing; active and inactive ingredient in beauty products and as a filter in paint, plaster, adhesives, and pharmaceutical.

\section{Experimental Methodology:}

Batch sorption studies were conducted to study the effect of Controlling, parameters like contact time, dosage and $\mathrm{pH}$, In order to investigate the mechanism of adsorption on sorption kinetics and recycle and reuse. All the experiments were conducted at room temperature $(30 \pm \mathrm{C})$. Fluoride concentration was estimated by SPADNS method using a
(SPECTROQAUNT

PHARO

300)

\subsection{Resultsanddiscussion \\ Batch Sorption Studies:}

\subsubsection{Effect of contact time}

Contact time has a greater influence in the adsorption process. the effect of contact time on removal of fluoride from synthetic sample using fuller's earth are shown in the figure 1.3.1. It may be observed from the Figure that as contact time increases, percent removal also increases initially and reduces gradually with time and attains almost an equilibrium condition in nearly $60 \mathrm{mins}$ with the removal efficiency of $71 \%$ in $100 \mathrm{ml}$ of sample.

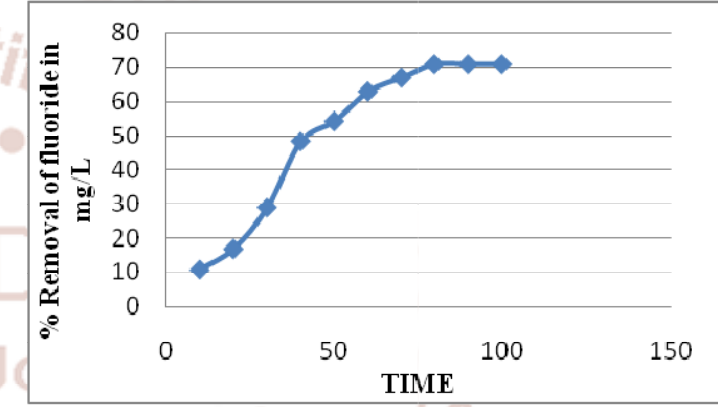

Fig. 1.3.1 Effect of Contact Time on Fluoride Removal by Fuller's Earth

\subsubsection{Effect of Adsorbent Dosage}

Adsorption is a process in which continues transfer of solute from solution to adsorbent occurs, until residual concentration of solution maintains equilibrium with that adsorbed by surface of adsorbent at constant contact time. Effect of adsorbent dosage is studied and graph of percentage of fluoride removal versus dosage is plotted .From graph it is observed that, as the dosage of fuller's earth increases, amount of residual fluoride decreases sharply and minimum the dosage, at which the maximum removal is attained, is taken as the optimum dosage. The optimum dosage or fuller's earth is $160 \mathrm{mg}$ with removal efficiency of $73 \%$ in $100 \mathrm{ml}$ of sample.

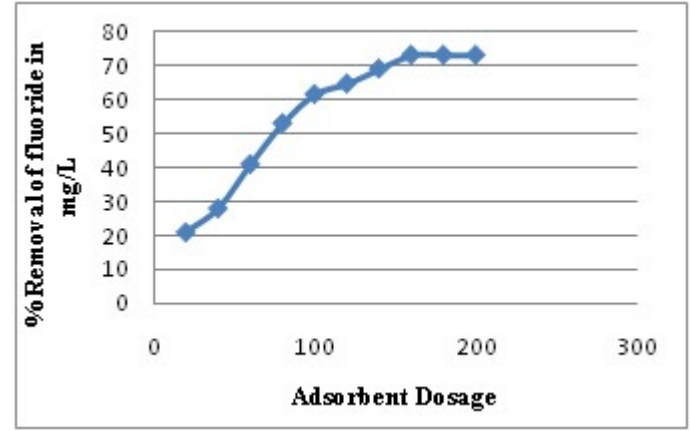

Fig.1.3.2 Effect of Adsorbent Dosage on Fluoride Removal by Fuller's Earth 


\subsubsection{Effect of pH on fluoride Removal}

The $\mathrm{pH}$ of the solution has influence on the extant of adsorption removal efficiencies of fluoride by fuller's earth at different $\mathrm{pH}$ values are shown in the table 4.3. As the $\mathrm{pH}$ increases, the removal efficiency increases as shown in figure 4.3. It has been observed that maximum adsorption takes place in the basic medium around $\mathrm{pH} 7.00$ and the removal efficiency of fuller's earth is $75.5 \%$ in $100 \mathrm{ml}$ of sample.

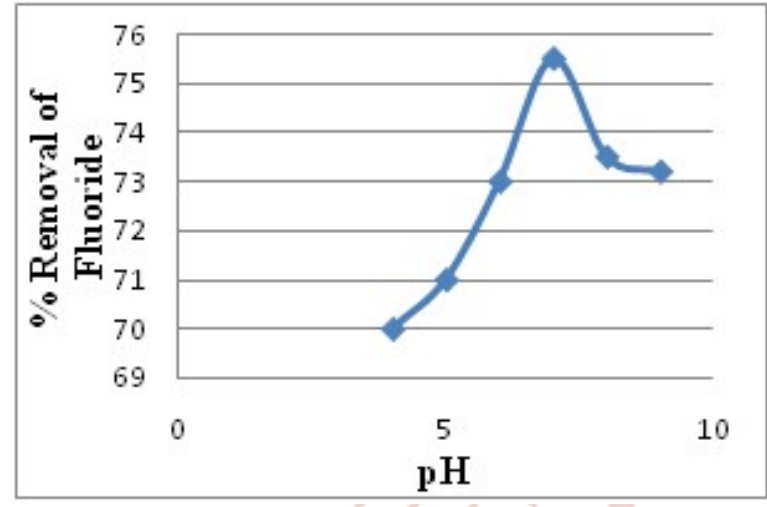

Fig.1.3.3 Effect of pH on Fluoride on Removal by Fuller's earth

\subsection{Sorption Kinetics}

The kinetics of fluoride removal was performed at constant temperature at different time interval of adsorption .The batch kinetic data for the adsorption of the fluoride was tested for the first order reaction .The rate equation for the first order reaction is given by levenspiel,

This produces a straight line graph with slope = $\mathrm{k} / 2.303$. From the value of graphical and Calculated $(\mathrm{K})$ values, it is observed that adsorption of fluoride follows first order rate equation

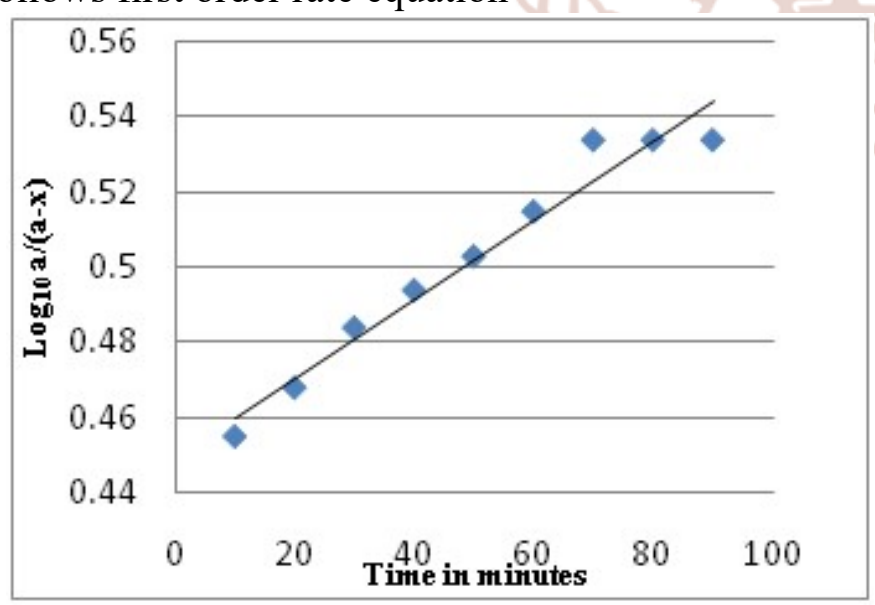

Fig 4.4. Plot of Reaction Rate Constant for Fuller's Earth

\subsection{Recycle and Reuse}

Recycling of used adsorbent: Used adsorbent was washed by three solutions separately, the three solutions were 1N HCL, 1N Noah and distilled water, The used adsorbent was collected by filtering through filter paper and added it to the above three solutions separately and stirred for 30minutes.After this stirring process the solution was filtered and reused for adsorption process. Recycling of adsorbent was carried out by stirring on magnetic stirrer. Following are the results obtained after reusing.

Table -1.5

Data showing comparison of Fluoride removal efficiency values of fuller's earth before and after recycling the adsorben

\begin{tabular}{|c|c|c|c|}
\hline Adsorbent & $\begin{array}{c}\text { Solution } \\
\text { used for } \\
\text { washing }\end{array}$ & $\begin{array}{c}\text { \% removal of } \\
\text { fluoride by } \\
\text { fresh } \\
\text { adsorbent }\end{array}$ & $\begin{array}{c}\% \text { removal } \\
\text { of fluoride } \\
\text { by recycled } \\
\text { adsorbent }\end{array}$ \\
\hline $\begin{array}{c}\text { Fuller's } \\
\text { Earth }\end{array}$ & 1 N HCL & $64 \%$ & $40 \%$ \\
\hline al JOUl & $\begin{array}{c}\text { 1N NAOH } \\
\text { Distilled } \\
\text { Water }\end{array}$ & $64 \%$ & $31 \%$ \\
\hline
\end{tabular}

\subsection{Sorption Equilibrium}

Sorption equilibrium isotherms are used for the estimation of the amount of sorbate needed for sorbing a required amount of sorbate from solution. The most widely used equations to present the adsorption data are Freundlich, Langmuir and temkin isotherm. The sorption equilibrium data are filled for all the three isotherms.

\section{a) Freundlich Isotherm}

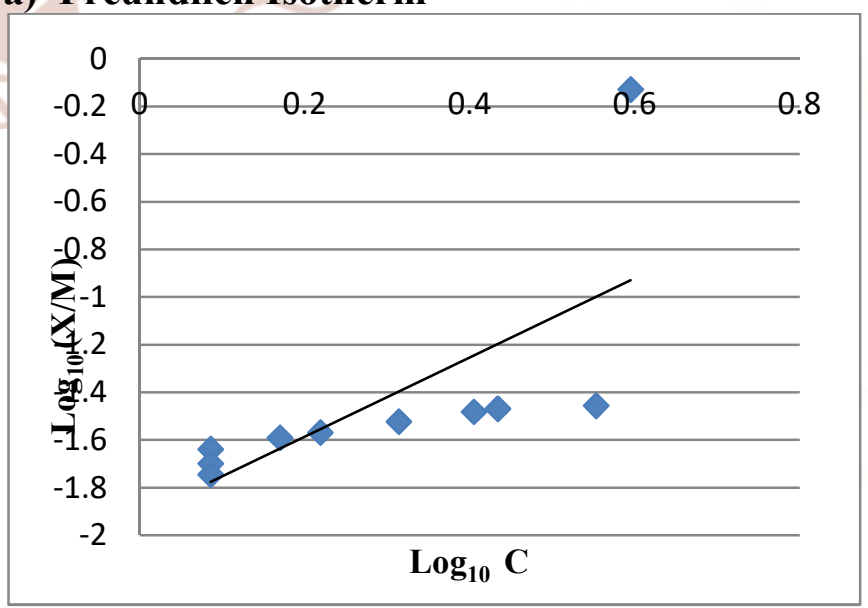

Fig. 1.6: Plot of Freundlich isotherm for Fuller's earth 
International Journal of Trend in Scientific Research and Development (IJTSRD) ISSN: 2456-6470

Table - 1.7 Constant of Freundlich Isotherm for Fuller's Earth

\begin{tabular}{|c|c|c|c|}
\hline $\begin{array}{c}\text { Adsorbe } \\
\text { nt }\end{array}$ & $\begin{array}{c}\text { Constant } \\
\text { "1/n" }\end{array}$ & $\begin{array}{c}\text { Constan } \\
\mathrm{t} \text { "n" }\end{array}$ & $\begin{array}{c}\text { Constant } \\
\text { "K" }\end{array}$ \\
\hline $\begin{array}{c}\text { Fuller's } \\
\text { Earth }\end{array}$ & 1.66 & 0.602 & 0.012 \\
\hline
\end{tabular}

\section{A) Langmuir isotherm}

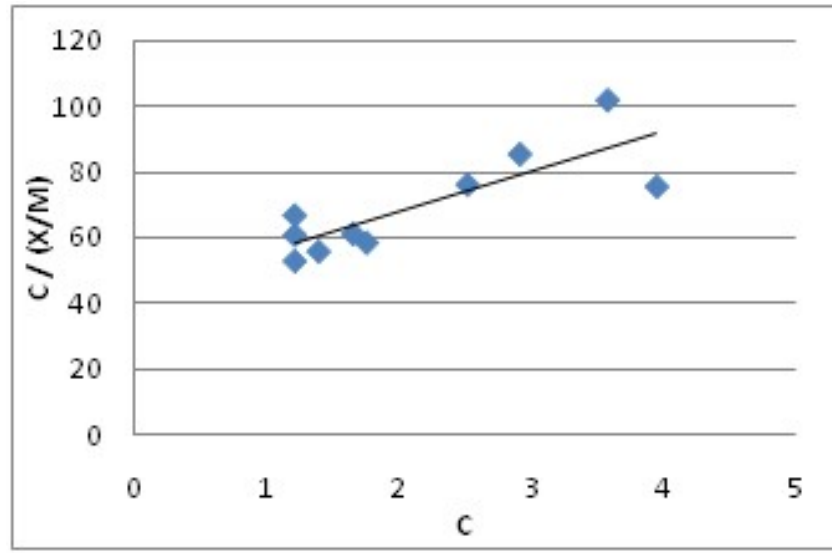

Fig 1.8: Plot of Langmuir Isotherm for Fuller's Earth

Table - 1.8 Constant of Langmuir Isotherm For Fuller's Earth

\begin{tabular}{|c|c|c|c|c|c|}
\hline $\begin{array}{c}\text { Adsor } \\
\text { bent }\end{array}$ & $\begin{array}{c}\text { Consta } \\
\text { nt "a" }\end{array}$ & $\begin{array}{c}\text { Consta } \\
\text { nt "b" }\end{array}$ & $\mathrm{R}$ & $\begin{array}{c}\text { Condi } \\
\text { tion }\end{array}$ & $\begin{array}{c}\text { Type of } \\
\text { isotherm }\end{array}$ \\
\hline $\begin{array}{c}\text { Fuller' } \\
\text { s Earth }\end{array}$ & 0.054 & -0.322 & 0.1 & $0<\mathrm{R} \iota$ & $\begin{array}{c}\text { Favoura } \\
\text { ble }\end{array}$ \\
\hline
\end{tabular}

\section{C) Temkin Isotherm}

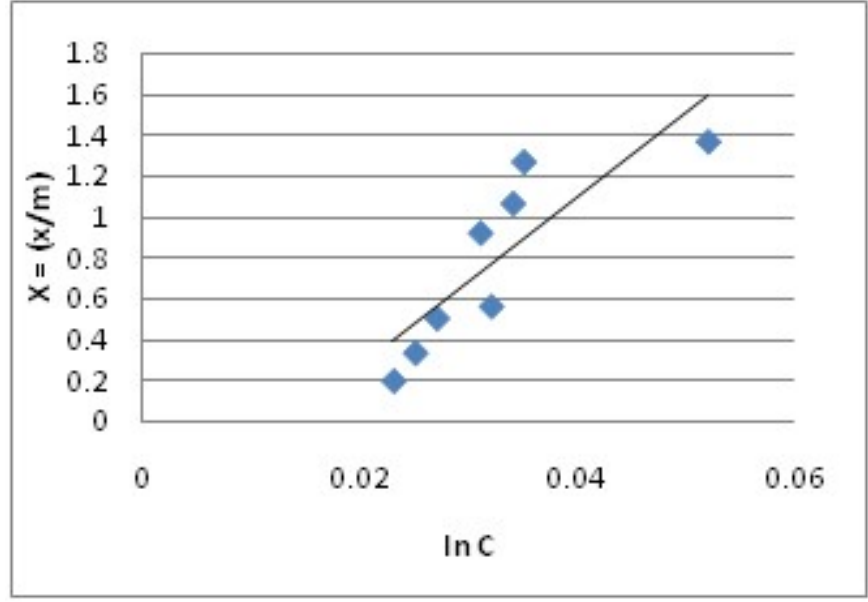

Fig 1.9: Plot of Temkin Isotherm for Fuller's Earth
Table -1.10

Constant of Temkin Isotherm for Fuller's Earth

\begin{tabular}{|c|c|c|}
\hline Adsorbent & Constant "a" & Constant "b" \\
\hline Fuller's Earth & 0.017136 & 0.01893 \\
\hline
\end{tabular}

\section{CONCLUSIONS}

From the results obtained during this study following conclusions were made

1. The Experimental result shows good removal efficiency of fluoride from synthetic solution by using fuller's earth.

2. The kinetics of adsorption of fluoride with fuller's earth was studied by estimating the effect of contact time on the percentage removal of fluoride. The data and results from the experiment used to removal of fluoride increase with increase in contact time and attains equilibrium at particular time. The optimum contact time for fuller's earth is 60 minutes with removal efficiency of $71 \%$ respectively.

3. The result of experiment on optimization of dosage of adsorbent reveals that, increase in amount of dosage added, increases the removal of fluoride from the solution. Optimum dosage for fuller's earth is $160 \mathrm{mg}$ with removal efficiency of $73 \%$ respectively.

4. The adsorption of fluoride is mainly $\mathrm{pH}$ dependent. The removal efficiency of adsorbent increases with decrease in $\mathrm{pH}$ value. It has been observed that maximum adsorption takes place in the basic medium around $\mathrm{pH}$ 7.00. For fuller's earth with removal efficiency $75.5 \%$ respectively.

5. The rate of adsorption of fluoride obeys first order rate equation. It also follows Webber equation .

6. The result of the batch experiments follows Langmuir $(\mathrm{R}<1)$, and Temkin isotherms but Freundlich isotherms $(1 / n>1)$ and $n<1$ proves to be an unfavourable adsorption.

\section{REFERENCE}

1. Keerthi. B. Gurani `Adsorption studies of Fluoride on Activated Carbon Derived from Phoenix Dactylifera (Date Plam) Seed ', M.E Env. Engg Dissertation work, P.D.A.C.E.G (2012). 